LI-SHA YE, Ph.D. Candidate ${ }^{1}$

E-mail: yelisha@nuaa.edu.cn

LI CAO, Ph.D. ${ }^{1}$

E-mail: caoli@nuaa.edu.cn

XU-HUI WANG, Eng. ${ }^{2}$

E-mail:wangxh@mail.castc.org.cn

${ }^{1}$ College of Civil Aviation

Nanjing University of Aeronautics and Astronautics

Nanjing, Jiangsu, 210016, China

${ }^{2}$ China Academy of Civil Aviation Science and Technology

Beijing, Beijing, 100028, China
Science in Traffic and Transport

Preliminary Communication

Submitted: 1 Mar. 2018

Accepted: 4 Apr. 2019

\title{
EVALUATING FUEL CONSUMPTION FOR CONTINUOUS DESCENT APPROACH BASED ON QAR DATA
}

\begin{abstract}
Fuel savings are a significant aspect for evaluating the current and future technologies of civil aviation. Continuous-Descent Approach (CDA), as a representative of new concepts, requires a method for evaluating its fuel benefits. However, because of unavailability of the practical operational data, it is difficult to validate whether the previous fuel consumption mechanisms are suitable. This paper presents a unique method for quantifying potential fuel benefits. This permits an easy evaluation for the new procedures without modelling before implementing field tests. The proposed method is detailed in this paper. It derives from the inherent mechanical characteristic of aircraft engine, and utilizes historical flight data, rather than modelling, to predict fuel flow rates by matching flight conditions from Quick Access Recorder (QAR) data. The result has been shown to predict fuel consumption for conventional descent with the deviation of $\pm 0.73 \%$. To validate such method, a case study for our designed CDA procedure is presented. Fuel consumptions in baseline scenarios are estimated to analyse the variable impacts on fuel consumption. The estimated fuel benefits are consistent with the results in the previous field tests. This analysis helps support Air Traffic Management decisions on eventual field test by reducing the validation time and cost.
\end{abstract}

\section{KEY WORDS}

fuel consumption; continuous descent approach; flight data;

\section{INTRODUCTION}

Today, the aviation industry releases $2 \%$ of the global $\mathrm{CO}_{2}$ emissions, and this is expected to increase with the continuous and steady growth of traffic flow. In the long term, the goal is to reduce its net carbon footprint by 50\% compared to 2005 [1]. Technological improvements leading to reduced emissions will continue in the future as well as the optimal use of airspace availability. Given such consideration as one of the significant targets, the USA and Europe propose some strategic plans, known as Next Generation (NextGen) [2, 3], Single European Sky ATM Research
(SESAR), respectively [4], and put highlights on new concepts and procedures to provide great environmental benefits [5-7].

One way of minimizing fuel consumption is via environment-friendly procedures such as Continuous-Descent Approach (CDA) [8-10]. It is essential to consider the impacts on the environment. Flight test is no doubt a straightforward and precise way to evaluate its fuel savings. However, it is hard to implement field tests due to its risk, the limitation of technical restriction and high cost. For instant, CDAs are usually implemented in low traffic density [11]. Here come a kind of simulation-based methods which can provide suggestions for the field test. A widely-known BADA (Base of Aircraft Database) fuel-flow model [12], which was developed by EUROCONTROL, has been dominantly used in several studies [13-15]. The BADA fuel consumption model has been shown to work well in cruise, within $5 \%$ of estimation error. However, at terminal altitude (below 11,000 feet MSL), the model is underestimated by $15-25 \%$ when compared to the manufacturer's data [16]. Also, it is unknown whether the existing fuel consumption mechanism is appropriate for new procedures, or research should be done in depth in studying their usability. (i.e. a near-idle thrust is used as its engine setting of CDA, and also does so for the range of reference data conditions, which are different from the conventional way, and yielding difficulty on parameters identification). Since BADA is a database derived from reference sources instead of field tests, errors are inevitable when estimating fuel consumption. Certainly, if abundant data could be acquired, the coefficients identification of BADA fuel burn model would be achieved using modelling techniques. Nevertheless, before the field test, actual operational data are not available, and the quality of the identified aircraft models depends directly on the quality of the reference data. In this case, if we simply use the model structures and coefficients provided by BADA Operations Performance File (OPF), or 
supposing a hypothesis that traditional data can be used to identify model coefficients, it will inevitably reduce the fidelity of the model and introduce significant error in the BADA model. It is worth noticing that precision of the performance (trajectory) data is critical to achieve good optimisation of drag, thrust and fuel flow coefficients. Also, the combined impacts on fuel consumption lead to its coupling nature for these parameters, and strong non-linearity makes it more difficult in modelling fuel consumption, and then the modelling work for fuel consumption can hardly be realized.

Aircraft is a reliable mechanical system with high repeatable inherent attribute under the same conditions, and flight data recorded by Flight Data Recorder (FDR) or Quick Access Recorder (QAR), are derived from actual operations and thoroughly reflect the real states of the aircraft. Enlightened from the above facts, a simulation-based approach called sub-match method is proposed in this research by utilizing historical QAR data directly and primitively, to estimate fuel consumption for the CDA. Without data supporting CDA, this paper emphasises studying an approach to simplify the modelling process, more than modelling, and further improving its usability and estimation accuracy. Besides, avoiding high-dimensional modelling, various influence factors on fuel consumption can be taken into consideration easily. This was accomplished by combining those variables to establish flight conditions, and then its corresponding fuel burn rates can be queried from QAR data records. For demonstrating how to use such method to estimate fuel consumption, a case study of Area Navigation-Continuous Descent Approach (RNAV-CDA) procedure of runway 17L at Pudong Airport has been analysed. Extracting the key parameters from profiles, quantities of fuel savings under several approach scenarios are calculated using the proposed method. Three main questions are investigated: first, how to determine which variables are essential for fuel consumption; second, how to utilize QAR data to match flight conditions; and third, how to ensure the accuracy and reasonability of estimation for the fuel burn.

This paper is organized as follows. Section 2 describes the methodology of sub-match method based on QAR data. Section 3 presents the way of fuel consumption analysis for the design of the CDA procedure. Section 4 provides the simulation results and the analysis. Finally, conclusions and future work are described in Section 5.

\section{PROPOSED SUB-MATCH FUEL CONSUMPTION METHOD}

In this Section, the principle of this method base is introduced. Then, the sub-match fuel consumption method is described by virtue of conducting simulation of four flights, to explain how to utilize QAR data to establish flight conditions and further estimate the fuel benefits.

\subsection{Methodology principle}

Aircraft engine is a mechanical device, and thus it has an inherent mechanical feature that equal quantity of fuel is consumed with identical flight states and environment during the same period. In other words, fuel burn rates are highly repeatable under the similar conditions. Here, similar conditions means meteorology, aircraft performance, and flight states vary within small ranges, which do not have great influence on fuel flow rate. The fuel flow rates corresponding to some flight states are kept constant with the same factors influencing fuel consumption. This characteristic inspires us to utilize abundant flight data, and further to propose this estimation method.

The QAR data are quite extensive in the breadth of variables contained, including hundreds of parameters. The fuel consumption characteristic varies with different phases of flight, such as climb, cruise and descent. This research focuses on the CDA procedure. Therefore, of interest to this study in particular are the following variables: airspeed, pressure altitude, gross weight, flight-path angle, longitudinal acceleration, vertical speed, wind speed along the track and total temperature.

In terms of the selected variables, the validation for this principle can be achieved as follows: the QAR data of two flights from one aircraft are extracted randomly from the database, and the data for the same condition are queried, which is shown in Table 1:

Table 1 - Illustration for variables of a sub-condition

\begin{tabular}{||l|c|}
\hline \multicolumn{1}{|c|}{ Variable } & Range \\
\hline \hline Pressure altitude [ft] & $8,000 \sim 9,000$ \\
\hline Vertical speed [ft/min] & $-2,250 \sim-1,750$ \\
\hline Gross weight [lb] & $135,360 \sim 139,359$ \\
\hline Longitudinal acceleration [g] & $0.02 \sim 0.04$ \\
\hline Airspeed [kt] & $270 \sim 290$ \\
\hline Flight path angle [deg] & $-4 \sim-1$ \\
\hline Wind speed along track [kt] & $-60 \sim-30$ \\
\hline Total temperature ${ }^{\circ} \mathrm{C}$ ] & $15.5 \sim 20.5$ \\
\hline
\end{tabular}

There are 49 and 35 pieces of records queried from two flights, respectively, and the corresponding fuel flow rates are derived. Further, the average of fuel burn rates is calculated with the consequence of $2,710.5$ $\mathrm{lb} / \mathrm{h}$ for one flight, and $2,742.2 \mathrm{lb} / \mathrm{h}$ for the other, and only with $1.1 \%$ difference between two flights, from which the principle has been proven. 


\subsection{Method details}

Based on such fundamental principle, Figure 1 illustrates the steps of fuel consumption estimation, and detailed explanations are stated as follows.

Step 1: Dataset is established by collecting historical QAR data during a certain period.

Step 2: The ranges of selected variables are segmented by their step sizes. The step sizes are required to confirm the estimation accuracy; too large ones will result in inaccuracy in the average of the fuel flow rate, while too small ones will generate too many sub-conditions, leading to lower matching percentage and querying speed. Thus, a trade-off must be made between them.

Step 3: Composing the segments of those variables with each other, several sub-conditions are derived, all of which cover the entire descent conditions in dataset. For instant, one of the sub-conditions is listed in Table 1, and several records within the ranges of such sub-condition are queried. And then each fuel burn rate value for one sub-condition is replaced by the average value of the queried fuel records of its sub-condition.

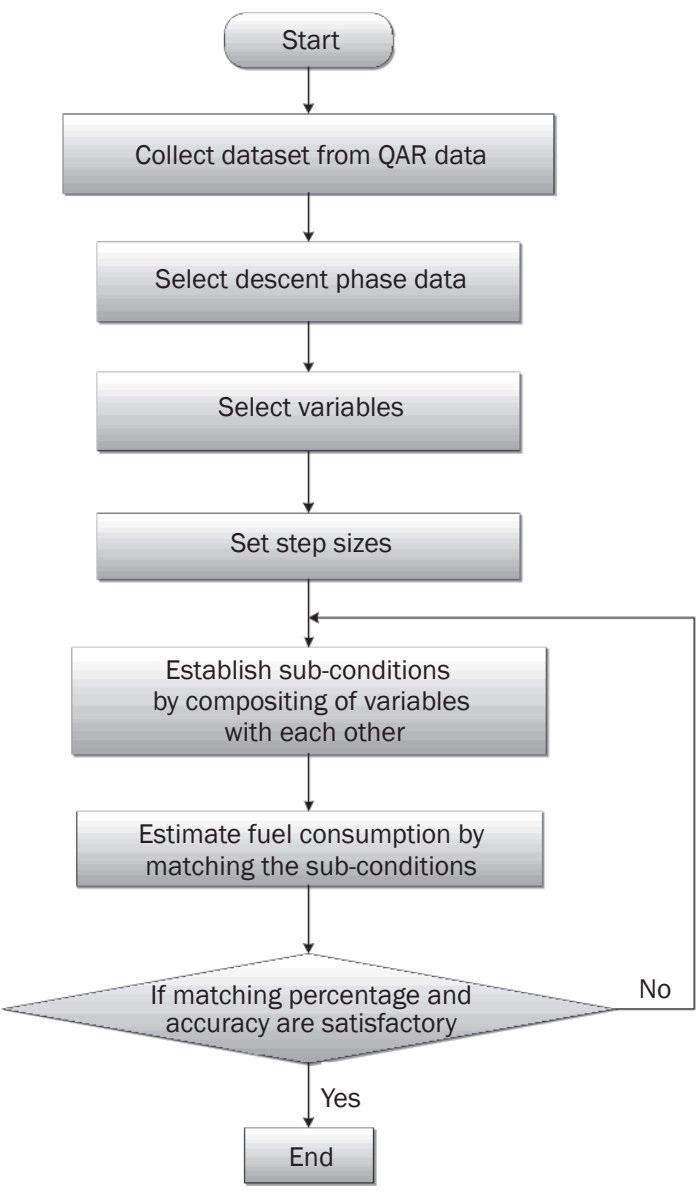

Figure 1 - Illustration of sub-match method
Step 4: Several flights are selected randomly for validation. Every record of its QAR data is queried from sub-conditions, and the query is finished when all the variables of every record have been matched up.

Step 5: Calculate the matching percentage and accuracy under this step size; if not acceptable, jump back to Step 2. The matching percentage (MP) means the percentage of validation data matched up with some record in the dataset, and tiny minority of validation data which cannot be matched up with any record are replaced by the average value of the adjacent ones.

In particular, two points have to be emphasized and explained on how to establish the dataset in Step 1 and how to determine the step size of variables in Steps 2 and 5.

1) Establishment of dataset

Sufficient data in a dataset indicate that as long as the matching percentage and estimation accuracy could be satisfied, it does not matter how huge the amount of data is. Moreover, for a certain period mentioned in Step 1, it refers to the performance of aircraft that can be treated as identical, without overhaul or engine replacement. Also, the meteorological condition remains unchanged. Further, in order to trace the performance degradation and meteorological change, the dataset is constantly being updated in a time window. Obviously, the dataset will be larger along with the longer period covered by the dataset.

2) Determination of the step size

In general, the step sizes of variables are determined iteratively until reaching the accuracy acceptability. As an initial attempt, the step sizes are acquired from the specialist experience of airline companies. The variables, such as longitude and airspeed, which have bigger influence on the fuel consumption, should be partitioned with subtle step size, and vice versa. For instance, in aircraft performance database, the interval of deviation from International Standard Atmosphere (ISA) is $5^{\circ} \mathrm{C}$. Hence, the step size is chosen as $5^{\circ} \mathrm{C}$ initially.

Based on that, further validation and modification will be processed. Take vertical speed for instance, $500 \mathrm{ft} / \mathrm{min}$ difference of FPA will lead to $8.55 \%$ of standard deviation of the fuel flow rate, while $10.89 \%$ of which will be generated by $600 \mathrm{ft} / \mathrm{min}$ difference of vertical speed. The standard deviation (STD) indicates the degree of fluctuation of data. For the predefined STD within $10 \%$, and hence, $500 \mathrm{ft} / \mathrm{min}$ is chosen roughly as the step size of vertical speed. This method can only provide rough ranges primitively.

Further, in order to confirm a group of appropriate step sizes with acceptable accuracy ultimately, by evaluating the estimation error, an experiment with test samples of 32 flights is conducted. The $95 \%$ 
Table 2 - Examples of determining the step size of variables

\begin{tabular}{|c|c|c|c|c||}
\hline Step size & MAPE [\%] & NRMSE [\%] & MP [\%] & $N$ \\
\hline \hline$[30,1000,0.05,4000,500,3,30,5]$ & 5.12 & 0.52 & 98.97 & 11,923 \\
\hline$[20,1000,0.05,4000,500,3,30,5]$ & 5.48 & 0.54 & 98.05 & 13,522 \\
\hline$[30,2000,0.05,4000,500,3,30,5]$ & 4.25 & 0.48 & 100.0 & 5,579 \\
\hline$[30,2000,0.04,4000,500,3,30,5]$ & 3.33 & 0.25 & 99.91 & 6,734 \\
\hline$[30,2000,0.03,4000,500,3,30,5]$ & 2.78 & 0.21 & 99.88 & 8,355 \\
\hline
\end{tabular}

$N$ : the number of sub-conditions

confidence interval for the predicted fuel flow rate per flight at a sampling instant is given by the inter-percentile range between the $2.5^{\text {th }}$ and the $97.5^{\text {th }}$ percentiles of the fuel flow rate samples. The metrics used to evaluate the models are as follows:

Mean Absolute Percentage Error (MAPE): It indicates $L_{1}$-norm accuracy of the mean estimation

MAPE $=\frac{1}{n} \sum_{1}^{n}\left|\left(\frac{f f_{i}-\widehat{f f f_{i}}}{\widehat{f f} f_{i}}\right)\right|$

where, $n$ is the number of the observation data in the test set, $f f_{i}$ is the measured value of fuel flow rate, $\widehat{f f} \widehat{f}_{i}$ is the estimated value.

Normalized Root Mean Squared Error (NRMSE): It indicates $L_{2}$-norm accuracy of the mean prediction.

$N R M S E=\frac{\sqrt{\frac{1}{n} \sum_{1}^{n}\left(f f_{i}-\widehat{f f f_{i}}\right)^{2}}}{\operatorname{std}\left(\widehat{f f}_{i}\right)}$

Here, $\operatorname{std}\left(\widehat{f f_{i}}\right)$ is the standard deviation of the vector of the mean predicted fuel flow rates.

The results having low MAPE, Iow NRMSPE and fewest sub-conditions are preferred. Specifically, five different groups of step sizes and their corresponding metrics results are shown in Table 2, to explain how to identify step sizes of the first three variables. The sequence of variables in Table 2 is airspeed, pressure altitude, longitude, gross weight, vertical speed, flight path angle, wind speed and total temperature, respectively. Indeed, the results listed in Table 2 are merely parts of dozens of tests, which have been done to identify the appropriate one. Take altitude for example, for the regulation of flight level interval $1,000 \mathrm{ft}$, so that the initial step size of pressure altitude chosen is $1,000 \mathrm{ft}$; too many sub-conditions will be generated. When the size is enlarged to $2,000 \mathrm{ft}$, the result can be seen from Table 2, yet the accuracy is increased by $0.87 \%$, along with statistically significant (at a $5 \%$ significance level) improvement. Besides, the number of sub-conditions is largely reduced.
In brief, determining the dataset and step size is a mutually iterative process, until reaching the predefined accuracy as well as the matching percentage, which indicates that a subtler step size requires a larger dataset. For this research, Boeing 737-800 QAR data of 300 flights have been integrated. According to the predefined requirement of estimation accuracy, it is found that at a $5 \%$ significance level, ultimately, the step sizes in the last row of Table 2 are chosen, giving the accuracy within $3 \%$ and the lowest NRMSE.

Then, according to the method principle mentioned previously: the fuel flow rates corresponding to some flight states are kept constant with the same factors influencing fuel consumption. The fuel flow rate can be obtained by querying and matching each sub-condition from the sub-match method. The results of the four flights from the test samples are presented in Table 3. The fuel flow rates are plotted in Figure 2.

Table 3 - Example results of sub-match method

\begin{tabular}{||c|c|c||}
\hline Flight No. & $M P[\%]$ & $M A P E[\%]$ \\
\hline \hline Flight 1 & 99.55 & 2.36 \\
\hline Flight 2 & 99.84 & 1.94 \\
\hline Flight 3 & 100.0 & 1.03 \\
\hline Flight 4 & 100.0 & 2.45 \\
\hline
\end{tabular}

\section{CASE STUDY: RNAV-CDA PROCEDURE OF RUNWAY 17L AT PUDONG AIRPORT}

Continuous-Descent Approach (CDA) is a pre-defined approaching procedure, in which the aircraft maintains near idle-thrust and continuous descent after Top of Descent (TOD), without any level-flight. Figure 3 shows the difference between the profile of conventional step-down approach and CDA. This section is dedicated to the estimation and analysis of potential fuel savings for our designed CDA procedure on the background of 17L Runway at Pudong Airport, using the sub-match method described in Section 2. 


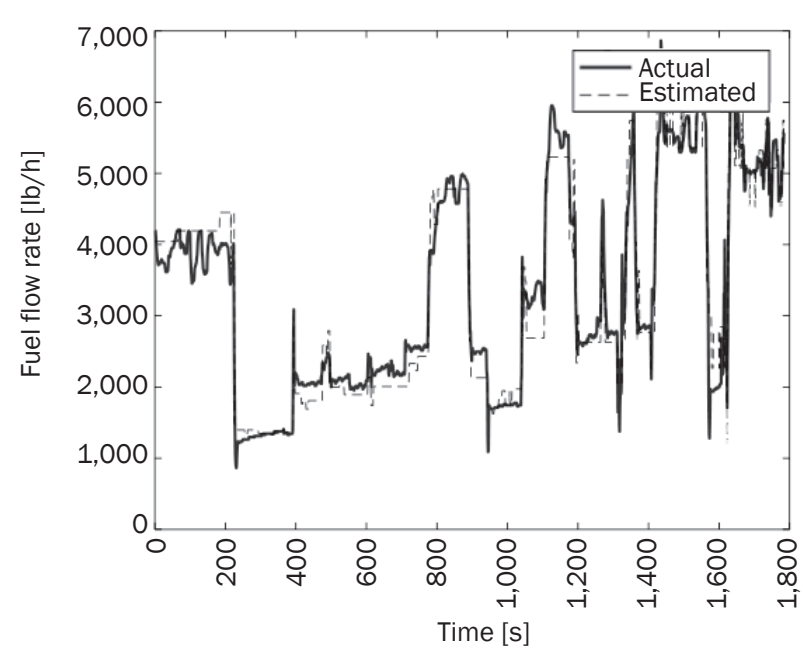

a) Flight 1

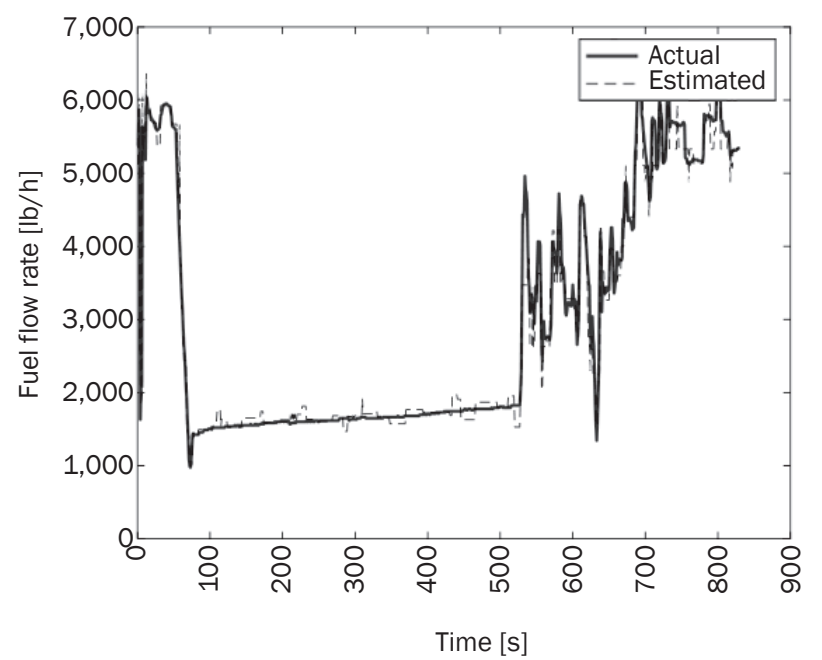

c) Flight 3

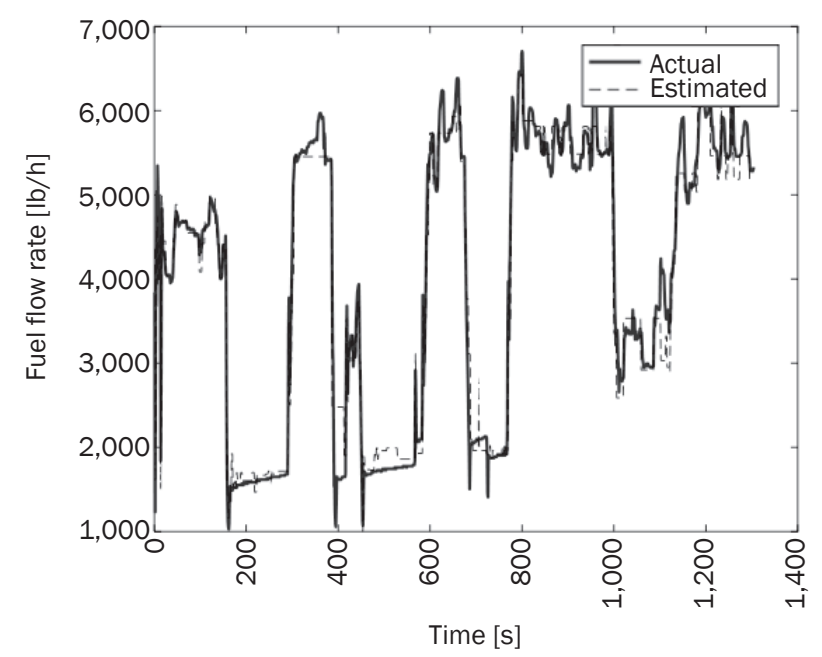

b) Flight 2

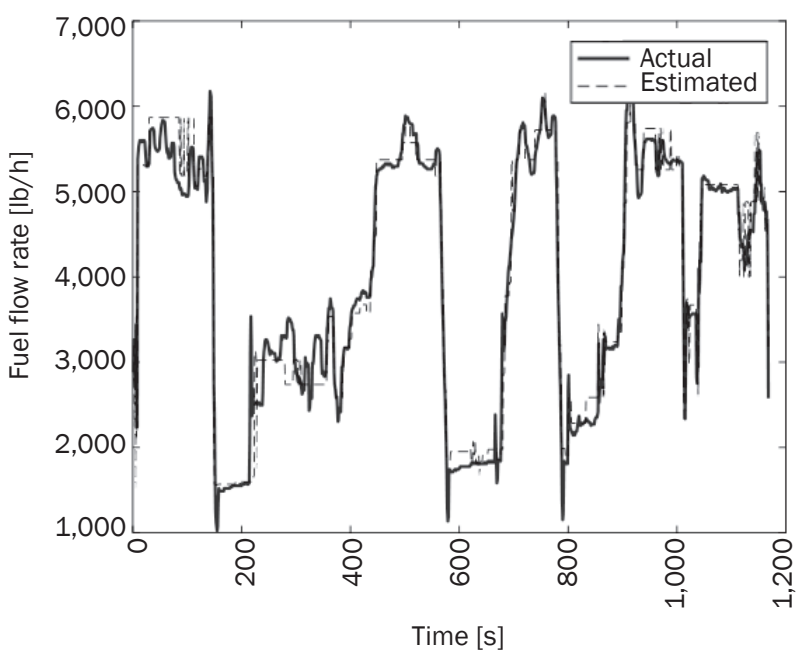

d) Flight 4

Figure 2 - Estimation of fuel flow rates for Boeing 737-800

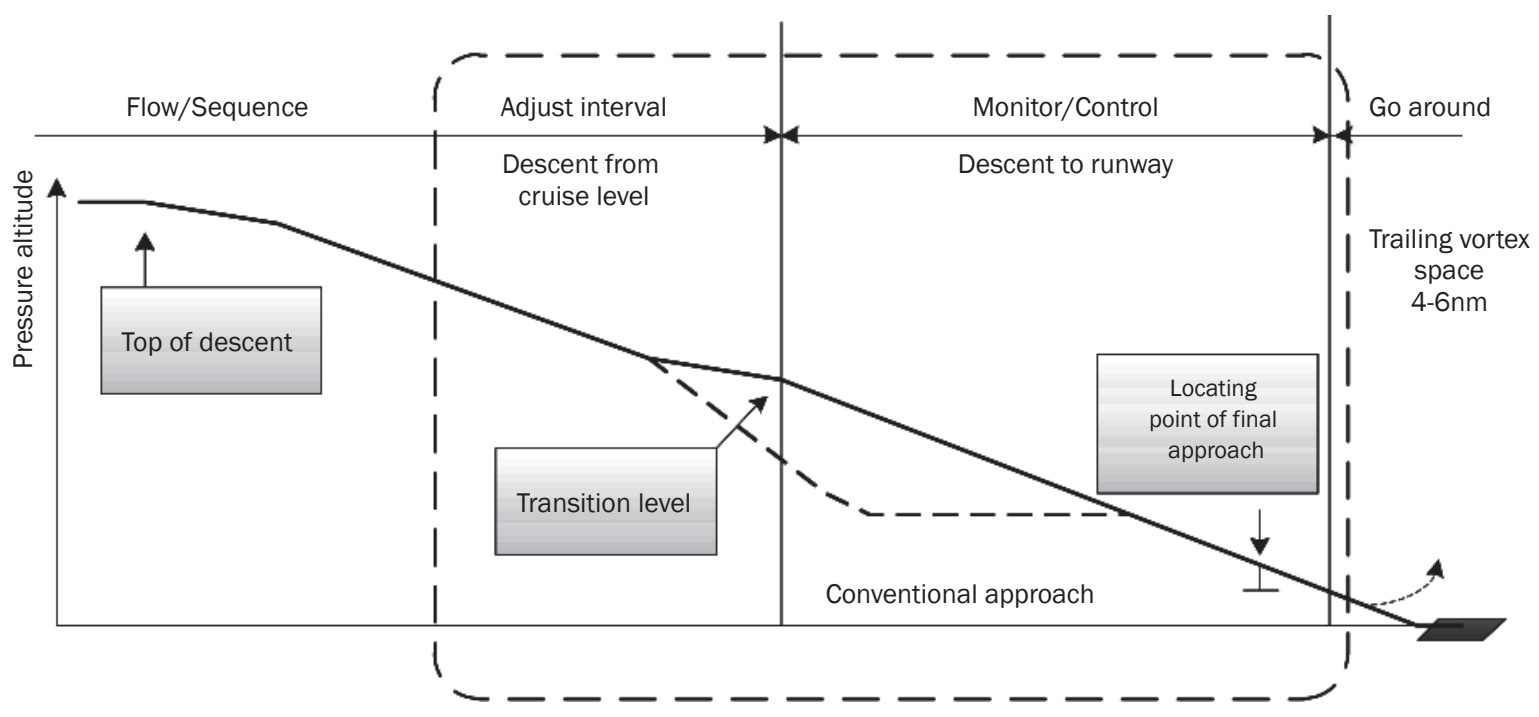

Figure 3 - Continuous Descent Approach 


\subsection{Procedure development}

The design of CDA procedure is based on the current implementation of RNAV procedure at Pudong Airport. By analysing the optimized CDA procedure designed by National Aerospace Laboratory of Netherlands (NLR) and Boeing Company, the optimal profile is plotted in Figure 4. Details of key points are described in Table 4.

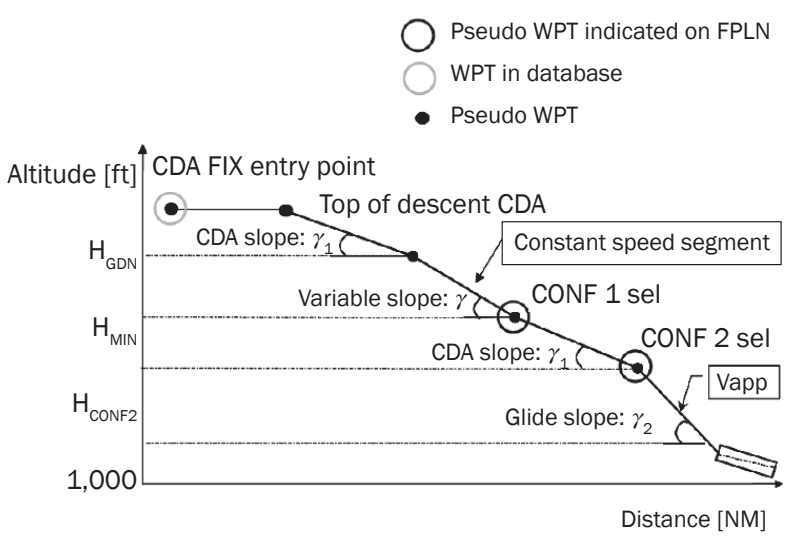

Figure 4 - The optimal descent profile

\subsection{Description of CDA profiles}

According to the facts discussed previously, several concerns with the fuel burn for Boeing 737-800 are specified by the following segments:

a) Landing point: According to the landing weight, flap position and runway information, the landing speed on $17 \mathrm{~L}$ runway is VREF40, and the $12 \mathrm{ft}$ is the altitude of the airport. b) The point of cutting in glide path: Intermediate arrival point is severed as the cutting in glide path point, the distance of which to entrance of runway is $21.3 \mathrm{~km}$, with the gliding flight path angle of $3^{\circ}$, the altitude of this point is $H_{I F-A G L}=21300 \cdot \tan 3^{\circ} \approx 3662$

Plus $12 \mathrm{ft}$ of height of airport, the altitude of point cutting in glide path $H_{I F-M S L}$ is 3,674 ft.

Calculating the speed of this point: The weight of IF point is assumed to be $143,000 \mathrm{lb}$, and the speed is $180 \mathrm{kt}$. By referring to the configuration and limited speed of B737-800 operation manual, it is noted that, when descending at this point with idle thrust, the speed should be at form " 5 ", that is (VREF40+30) kt.

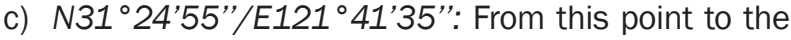
point of cutting in glide path, the segment is the phase of gliding in speeding down. The speed at this point is VREF40+50 (200 kt), at form “1". According to the descent performance of B737-800, it is concluded that the starting altitude should be $4,593 \mathrm{ft}$, which is the tangent of the tuning segment.

d) N31 '24'38'" $E 121^{\circ} 33^{\prime} 45^{\prime \prime}$ : From this point to the point of cutting in glide path, the segment starts gliding in constant speed. The speed of this point is equal to the speed of tangent of the tuning segment, which is VREF40+50 (200 kt). According to the descent performance of B737-800, the start altitude is concluded as $5,577 \mathrm{ft}$, which is a crossing over point for the starting point of four sides.

e) PK: From this point to the altitude of $5,577 \mathrm{ft}$, the segment starts gliding with speeding down. By referring to the related manual, the speed of such

Table 4 - Demonstration of the optimised CDA procedure

\begin{tabular}{|c|c|}
\hline Start altitude $[\mathrm{ft}]$ & Procedure description \\
\hline $7,000 \mathrm{ft} \mathrm{AGL}$ & $\begin{array}{l}\text { Starting point: Max(210kt CAS, GD-speed), Conf 0, Ldg Up } \\
\text { Level flight to TOD }\end{array}$ \\
\hline $7,000 \mathrm{ft} \mathrm{AGL}$ & $\begin{array}{l}\text { Flight path angle (FPA): }-2^{\circ} \text { or }-2.5^{\circ} \text {, Idle thrust } \\
\text { Slow down to GDN-speed* }\end{array}$ \\
\hline $\mathrm{HGDN} * *$ & $\begin{array}{l}\text { Keep constant speed, alter FPA } \\
\text { Descent to HMIN, } \rightarrow \text { CONF2 }\end{array}$ \\
\hline $\mathrm{HMIN} * * *$ & $\begin{array}{l}\text { Flight path angle (FPA): }-2^{\circ} \text { or }-2.5^{\circ} \\
\text { Slow down to SN-speed } * * * * \rightarrow \text { CONF2 }\end{array}$ \\
\hline$\sim 3,000 \mathrm{ft}$ & Cut in glide path \\
\hline Below 3,000 ft & $\begin{array}{l}\text { F-speed } \rightarrow \text { CONF3, If CONF3 } \rightarrow \text { L/G down } \\
\text { F-speed } \rightarrow \text { CONF FULL, Slow down to Vapp }\end{array}$ \\
\hline Upon reaching Vapp $* * * * *$, above $100 \mathrm{ft}$ & $\begin{array}{l}\text { Descent at constant speed } \\
\text { Alter thrust, keeping } 3^{\circ} \mathrm{G} / \mathrm{S} \\
\text { Procedure terminates at } 50 \mathrm{ft} \mathrm{AGL}\end{array}$ \\
\hline
\end{tabular}

* GDN-speed: green dot speed, which is greater or equal to 1.25Vs (stall speed)

** HGDN is decided by two factors: GD-speed and FPA, and FPA depends on aircraft type and gross weight

$\star \star *$ HMIN is the minimum altitude keeping stable at 1,000ft AGL for the given weight

$\star \star * * \mathrm{SN}$-speed is S speed, which is the speed at configuration of F1 for airbus

$\star \star * * *$ Vapp is the final approach speed 


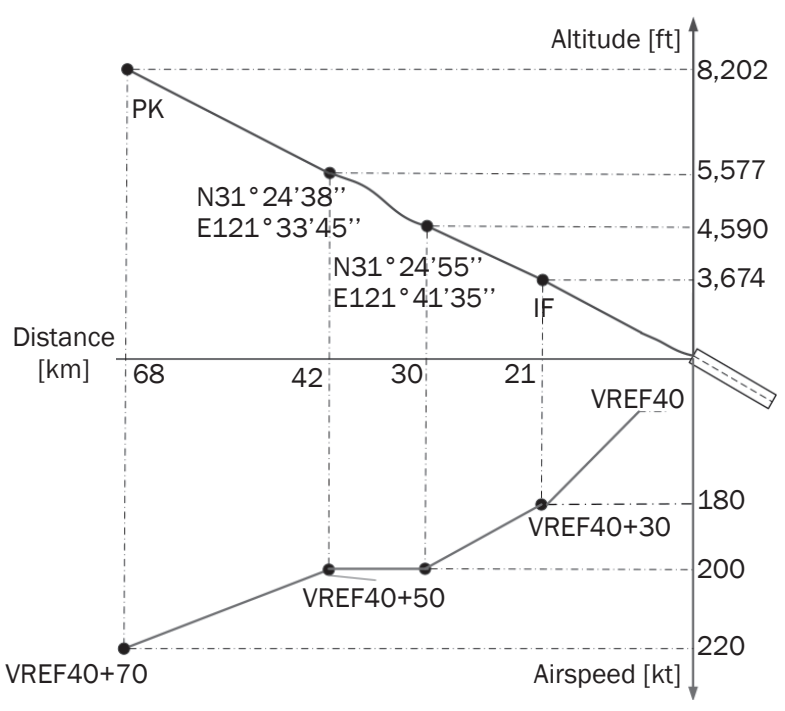

Figure 5 - Vertical trajectory and speed profiles of CDA procedure for runway $17 \mathrm{~L}$ at Pudong International Airport

point is VREF40+70, which is $220 \mathrm{kt}$, and the altitude is fixed at 8,202 $\mathrm{ft}$.

Analysing from the previous descriptions, the vertical trajectory and speed profiles can be drawn as in Figure 5.

\section{ESTIMATION OF FUEL CONSUMPTION FOR CDA PROCEDURE}

This Section is dedicated to the estimation of fuel savings resulting from CDA. Potential benefits of CDAs for twelve flights will be evaluated using sub-match method based on QAR data. Our scheme as described in Section 3 is further implemented by a detailed simulation for the case study for the CDA procedures. The conventional step-down trajectories recorded in QAR data serve as baselines for the comparison. In particular, five representative ones in this Section are analysed in depth. Additionally, the impacts of wind and different gross weights on fuel consumption are studied. The purpose is to examine whether CDA are capable of fuel savings under various conditions.

\subsection{Technical scheme}

Following the above guideline, the technical scheme for analysing fuel consumption of RNAV-CDA procedure is illustrated in Figure 6 . The details are described as follows:

a) Establishment of the approach environment: Several variables related to flight environment are recorded in QAR of sample flights, which can be used to establish the identical environment. In addition, the CDA procedure adopts the way of RNAV-CDA, and for conventional approach, actually, the mode of RNAV is used in instrument approach, which is VOR/DME approach procedure, and runway $17 \mathrm{~L}$ at Shanghai Pudong airport already has such a procedure.

b) Parameters of approach key point related to fuel consumption: The consumed fuel is driven by aircraft performance, flight states and environment. For identical performance, the given environment and gross weight, other key factors such as flight altitude, speed and attitude, are extracted from the key point of trajectory profiles, which play the most significant roles in the determination of fuel consumption.

c) Fuel consumption estimation method: With the selected variables and environment, sub-match fuel consumption method as described earlier is employed. How to match the given conditions could be a critical step for this method.

d) Comparison and analysis of the fuel consumption estimation: According to the quantities of fuel consumption calculated by sub-match method for two approach ways, the fuel savings capability for the CDA is explored.

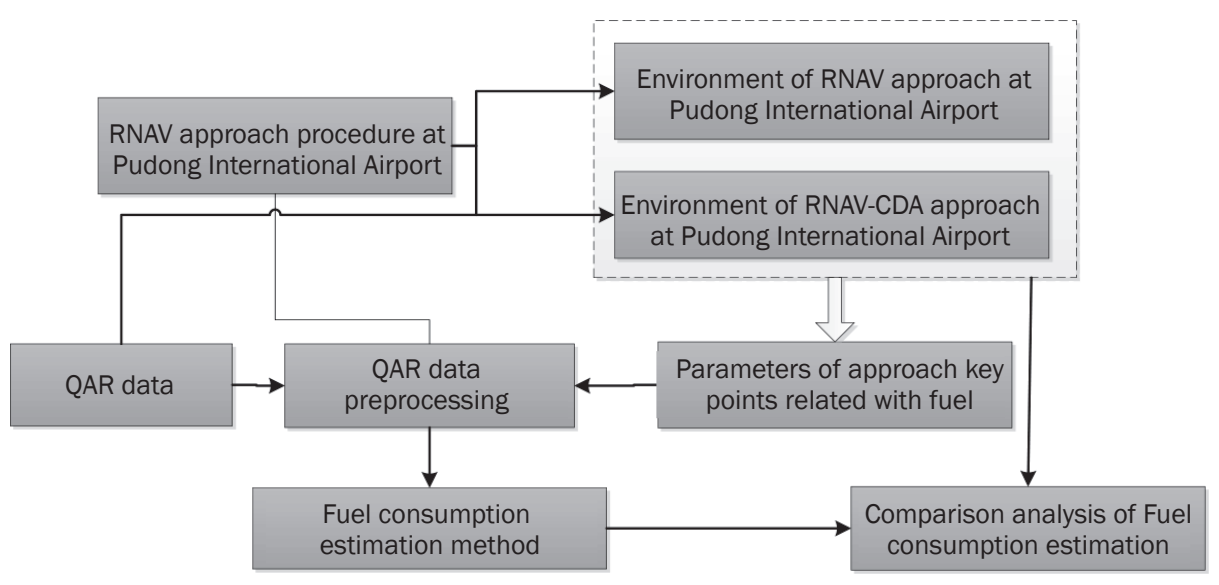

Figure 6 - Scheme of fuel consumption analysis 


\subsection{Data preparation}

Except for the dataset issues mentioned in Section

3, two highlights are emphasised as follows:

- For this research, QAR data of one identical B737800 from actual flights, covering the whole year during descent phase are collected as dataset.

- Twelve flights are used for validation samples, which are in the same period with the dataset, to guarantee that the aircraft performance is almost unchanged and cover the meteorology of validation flights.

\subsection{Establishment of experimental scenarios}

In order to analyse various environments for a whole year, twelve flights in each month are prepared for calculating the potential fuel savings of CDAs. In particular, five representative flights are selected to illustrate the details, which are marked by $A$ to $E$, respectively, for reasons of convenience.

Approach conditions are established by their meteorological and flight states data, which are listed in Table 6. Wind speed and aircraft weight play significant roles in the determination of fuel consumption. Hence, aiming to establish various scenarios to test the impact of these parameters, three considerations are given to establish the experimental scenarios:

1) The comparability for two types of approach procedures

As illustrated in Figure 1, sharing the same initial altitude and position, the starting point for both approach trajectories is set to be TOD. From the conventional approach procedure, the key points of horizontal and vertical trajectories for CDA procedures can be determined. Besides, the initial gross weight and meteorological environment of CDA are set to be identical to the conventional procedure.

2) Impact of wind speed

It takes positive values for tailwind and negative for headwind, noticing that the meteorological of flight
$\mathrm{A}, \mathrm{B}, \mathrm{C}$ and $\mathrm{E}$ are tailwind and the average of wind speed of flight $C$ is $69.4 \mathrm{kt}$, while flight $D$ is undergoing tailwind.

3) Impact of gross weight

The conditions of flights A and B are similar except for gross weight, which can be seen from Table 5; that flight A has a bigger gross weight. Such two scenarios will be taken to investigate whether the heavy aircraft will benefit from more fuel savings due to CDA.

\subsection{Extraction of the key points parameters}

On the premise of identical simulation environment, the main parameters of the key points are pressure altitude and airspeed. In Section 3, the designed RNAV-CDA procedure clarified the values of these parameters from 8,202 $\mathrm{ft}$ (PK point in Figure 6) to the landing point. Additionally, the altitude above the sea level should be calculated into pressure altitude. The vertical speed and longitudinal acceleration can be inferred from vertical and speed profile, respectively.

The initial approach times have to be confirmed as well. In practice, as described in the definition of CDA, however, the additional segment starting from cruise to $\mathrm{PK}$, should be taken into consideration, which is clearly different from the conventional approach (shown in Figure 1). Therefore, unification is necessary for the comparisons. In this research, for their common initial time, the point is selected which begins to descent from cruise and can be confirmed from QAR data. Hence, the additional segment (from initial point of CDA to the point of conventional approach) will be added when calculating fuel consumption for the conventional approach. The parameters of the key points for fuel burn estimation of runway $17 \mathrm{~L}$ at Pudong Airport is illustrated in Figure 7.

Table 5 - Approach conditions of conventional approach for five flights

\begin{tabular}{||l|c|c|c|c|c||}
\hline & Flight A & Flight B & Flight C & Flight D & Flight E \\
\hline \hline Vertical speed [ft/min] & $-3,222 \sim 227$ & $-3,269 \sim 56$ & $-3,397 \sim 222$ & $-2,394 \sim 272$ & $-1,748 \sim-704$ \\
\hline Pressure altitude [ft] & $-329 \sim 25,943$ & $-603 \sim 25,988$ & $-422 \sim 24,483$ & $-407 \sim 21,841$ & $-161 \sim 28,104$ \\
\hline Longitudinal acceleration [g] & $-0.06 \sim 0.156$ & $-0.053 \sim 0.11$ & $-0.057 \sim 0.082$ & $-0.01 \sim 0.148$ & $-0.038 \sim 0.14$ \\
\hline Airspeed [kt] & $142 \sim 369$ & $142 \sim 378$ & $144 \sim 419$ & $145 \sim 392$ & $146 \sim 429$ \\
\hline Initial gross weight [lb] & 128,600 & 136,838 & 133,239 & 135,640 & 129,240 \\
\hline Flight path angle [deg)] & $-4.21 \sim 0.69$ & $-5.32 \sim 0.40$ & $-5.27 \sim 0.35$ & $-6.33 \sim 0.70$ & $-5.98 \sim 0.35$ \\
\hline Along-track wind speed [kt] & $-8.4 \sim 53.6$ & $-9.9 \sim 65.9$ & $-8.9 \sim 102.0$ & $-46.2 \sim 9.4$ & $-3.4 \sim 94.7$ \\
\hline Average wind speed [kt] & 19.6 & 22.6 & 69.4 & -37.8 & 57.2 \\
\hline Total temperature [ $\left.{ }^{\circ} \mathrm{C}\right]$ & $-12.8 \sim 9.0$ & $-14.2 \sim 8.5$ & $-5.5 \sim 8.5$ & $-3.5 \sim 12.0$ & $-5.1 \sim 16.5$ \\
\hline $\begin{array}{l}\text { Distance of TOD point from } \\
\text { RWY17L threshold }[\mathrm{km}]\end{array}$ & 280.717 & 291.940 & 262.691 & 266.782 & 290.920 \\
\hline
\end{tabular}




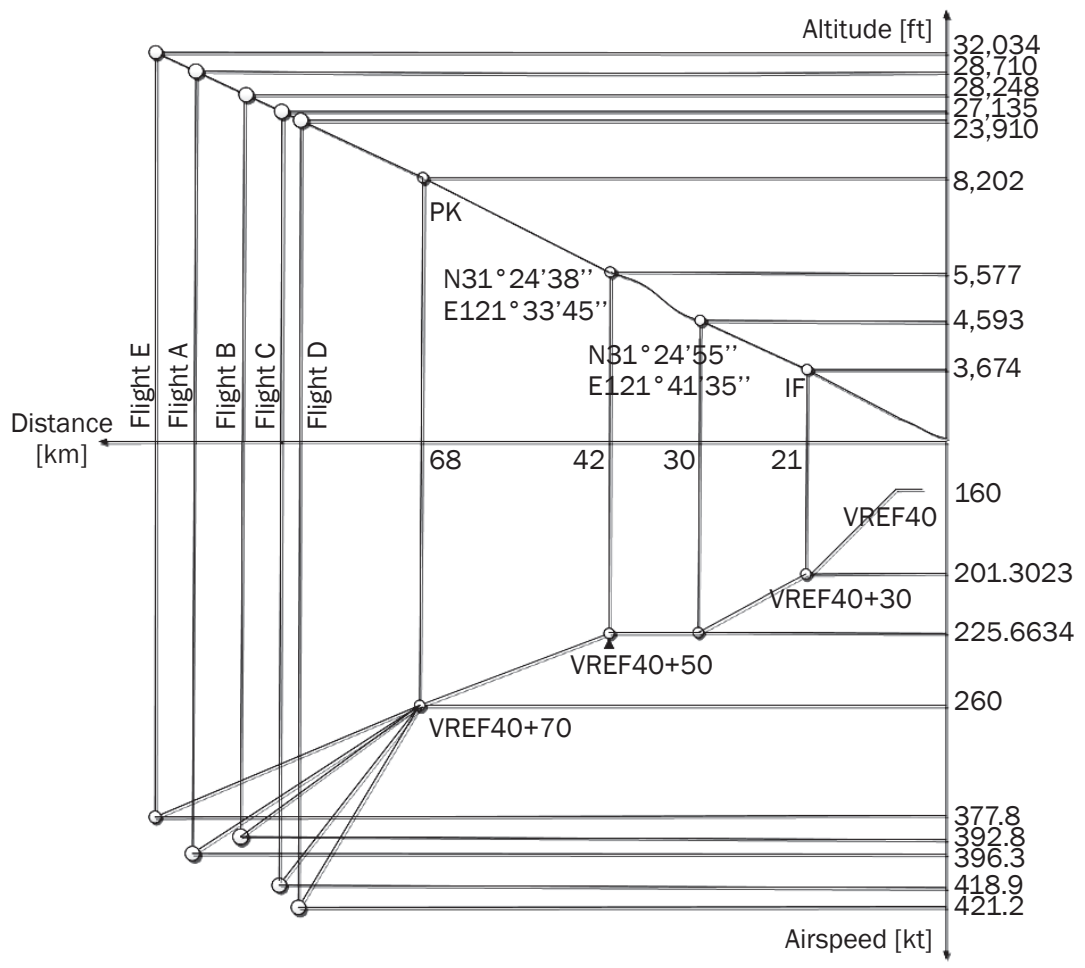

Figure 7 - Parameters of the key points for $A \sim E$ flights

\section{SIMULATION RESULTS AND ANALYSIS}

The fuel consumption and flight time of two approach patterns for sample flights are summarized in Table 6. The quantities of conventional approach are calculated by statistic values from QAR data, and for CDAs, the estimated values are the average values of the fuel burn records for each corresponding sub-condition, deriving from the method in this paper. The simulation results show that the average fuel savings of $217 \mathrm{lb}(98.6 \mathrm{~kg})$ per flight are achieved, almost 13.3\% less than in the conventional procedure. However, for unavailability of practical operational data, thus roughly, a cross-study comparison is made, and the chosen studies are comparative in the sense of standard procedure under the unconstrained traffic condition. As expected, the results are within or close to the ranges of the results from field tests of the CDA at Schiphol airport [17]. These reported that the box-plot of the historical data from FMS shown indicate that the fuel savings per flight for Boeing 738 s have lower quartile of $198 \mathrm{lb}(90 \mathrm{~kg})$ and the upper quartile of 286 Ib (130 kg). In addition, the actual flight arrivals into Denver International Airport (DEN) in October 2007 reported that a reduction of $250 \mathrm{lb}(113 \mathrm{~kg}) /$ flight for B738 was achieved from the flight level of 25,000 ft [18]. And Clarke et al. reported average fuel savings of $208 \mathrm{lb}$ per flight for large turbojets [19].

However, from the distribution of the estimated fuel savings visualized in Figure 8, the standard deviations are large, and thus, a deeper investigation into this estimation should be made. Additionally, five
Table 6 - Fuel consumption of two approach patterns

\begin{tabular}{||l|c|c|c||}
\hline \multicolumn{1}{|c|}{ Date } & $\begin{array}{c}\text { Fuel burn of } \\
\text { conventional } \\
\text { approach } \\
{[\mathrm{kg}]}\end{array}$ & $\begin{array}{c}\text { Fuel burn } \\
\text { of CDA } \\
{[\mathrm{kg}]}\end{array}$ & $\begin{array}{c}\text { Fuel } \\
\text { savings } \\
{[\mathrm{kg}]}\end{array}$ \\
\hline \hline $2 / 1 / 16$ (flight A) & 629 & 582 & 47 \\
\hline $12 / 2 / 16$ (flight B) & 819 & 629 & 190 \\
\hline $7 / 3 / 16$ & 689 & 564 & 125 \\
\hline $15 / 4 / 16$ (flight C) & 611 & 643 & -32 \\
\hline $23 / 5 / 16$ (flight D) & 755 & 586 & 169 \\
\hline $3 / 6 / 16$ & 802 & 724 & 78 \\
\hline $3 / 7 / 16$ (flight E) & 749 & 689 & 60 \\
\hline $8 / 8 / 16$ & 755 & 635 & 120 \\
\hline $22 / 9 / 16$ & 726 & 654 & 72 \\
\hline $5 / 10 / 16$ & 733 & 738 & -5 \\
\hline $28 / 11 / 16$ & 835 & 655 & 180 \\
\hline $9 / 12 / 16$ & 814 & 635 & 179 \\
\hline Total & 8,917 & 7,734 & 1,183 \\
\hline
\end{tabular}

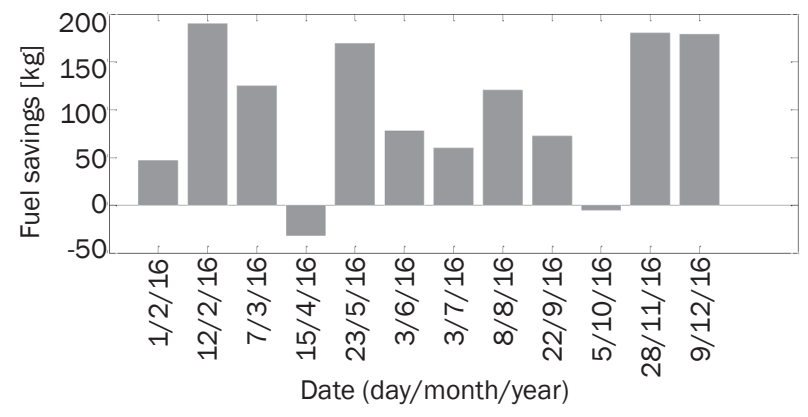

Figure 8 - Gross fuel savings for twelve sample flights 


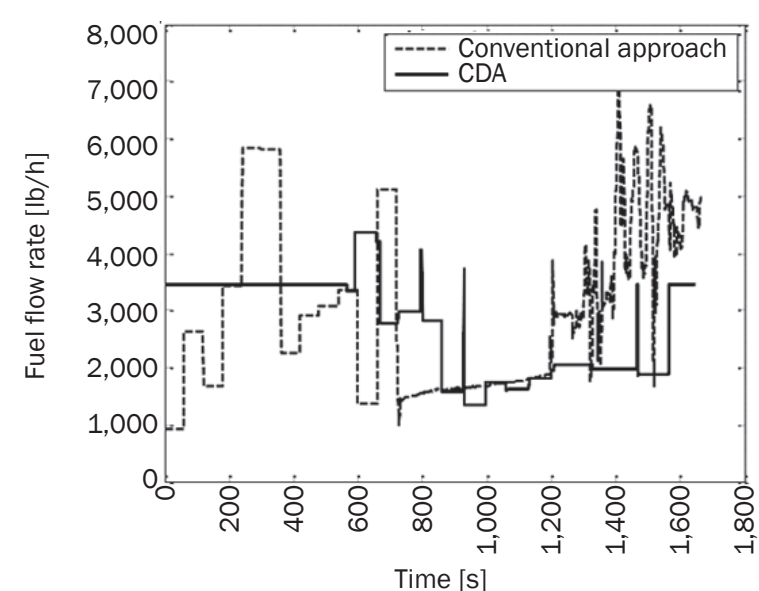

a) Flight $A$

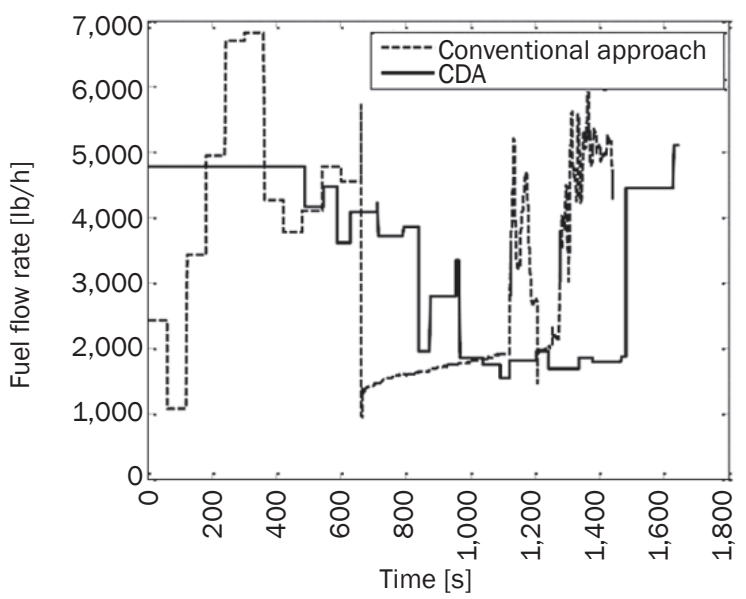

c) Flight $C$

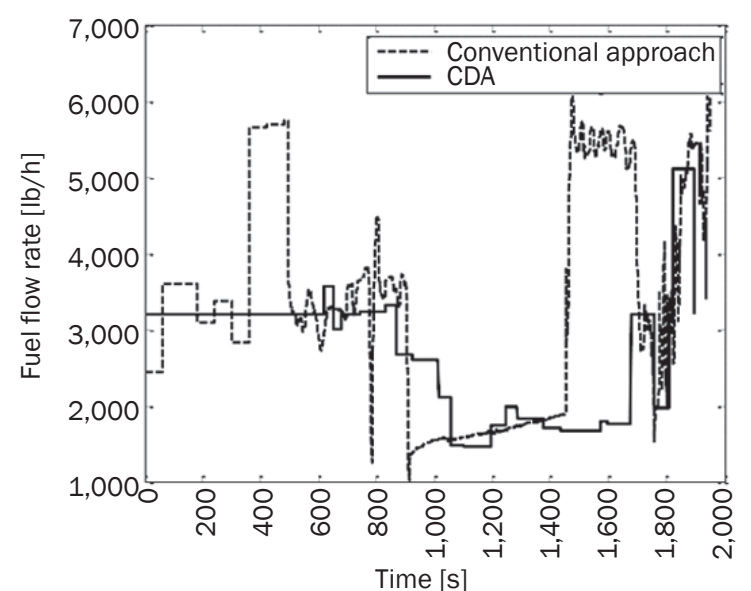

b) Flight $B$

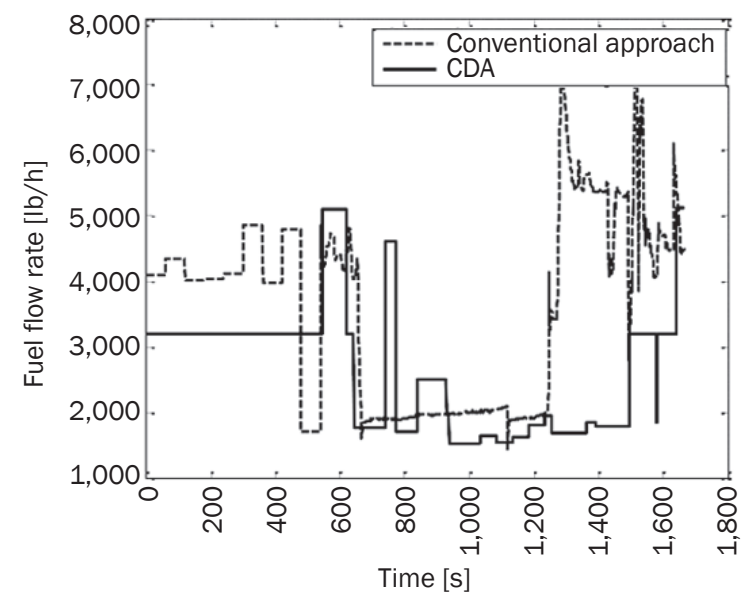

d) Flight $D$

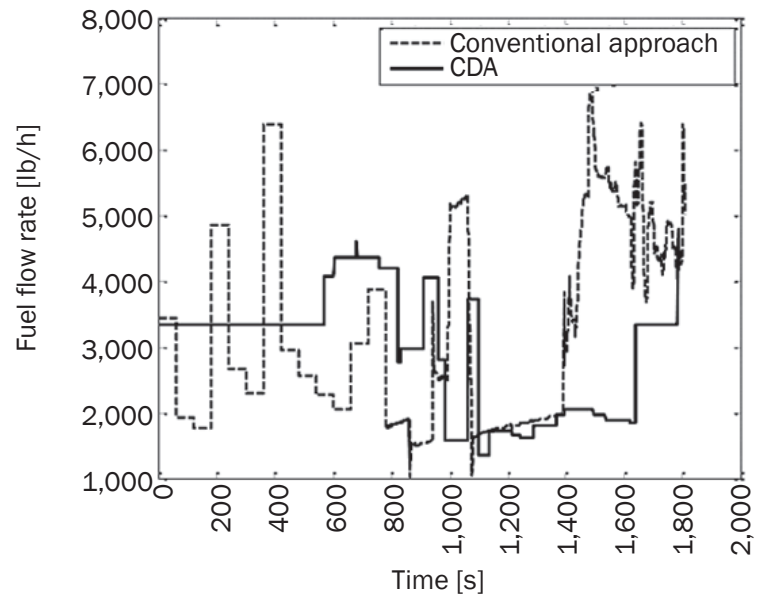

e) Flight $E$

Figure 9 - Fuel burn rates of two approach patterns

Table 7 - Fuel consumption of five representative flights

\begin{tabular}{||l|c|c|c|c|c||}
\hline & Flight A & Flight B & Flight C & Flight D & Flight E \\
\hline \hline Fuel burn quantities of conventional approach [lb] & 1,387 & 1,806 & 1,346 & 1,665 & 1,652 \\
\hline Fuel burn quantities of CDA [Ib] & 1,283 & 1,387 & 1,418 & 1,292 & 1,519 \\
\hline Fuel saving quantities [Ib] & 104 & 419 & -72 & 373 & 133 \\
\hline Percentage of fuel saving [\%] & 7.54 & 23.14 & -5.35 & 22.40 & 8.05 \\
\hline Time reductions [s] & 96 & 107 & -182 & 9 & 79 \\
\hline
\end{tabular}


representative flights, whose results are listed in Table 7 , selected from twelve samples are chosen to analyse the reasons.

Before revealing the results, it should be noted that the sampling time for the previous few records of QAR data (which represents transition segment from cruise to descent, about 6 to 13 records for five test flights) is

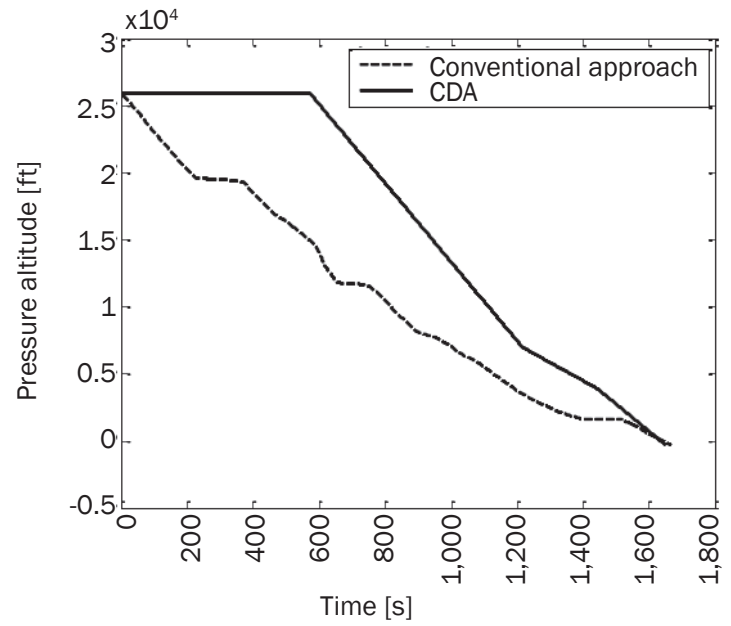

a) Flight $A$

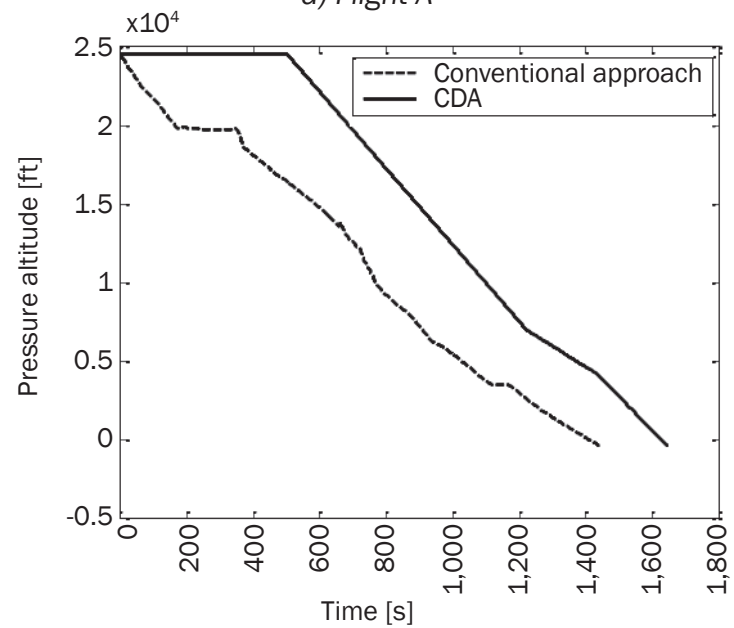

c) Flight $\mathrm{C}$
60 seconds, while in the later period they are sampled for one second, and as such, data interpolation should be made for the previous period.

Overall, as shown in Figure 9, the CDA exhibits lower fuel burn rates when comparing with the conventional approach. In most cases, the flight times of the CDA are also reduced. Figure 10 shows the vertical

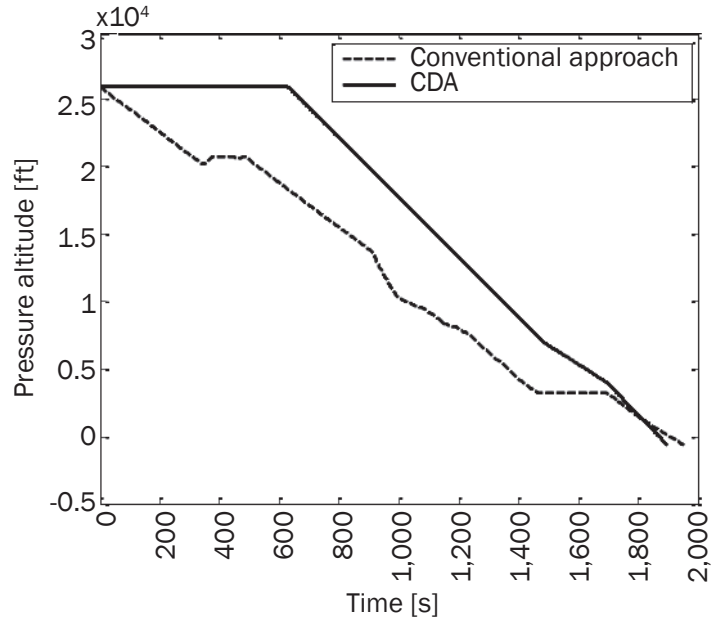

b) Flight $B$

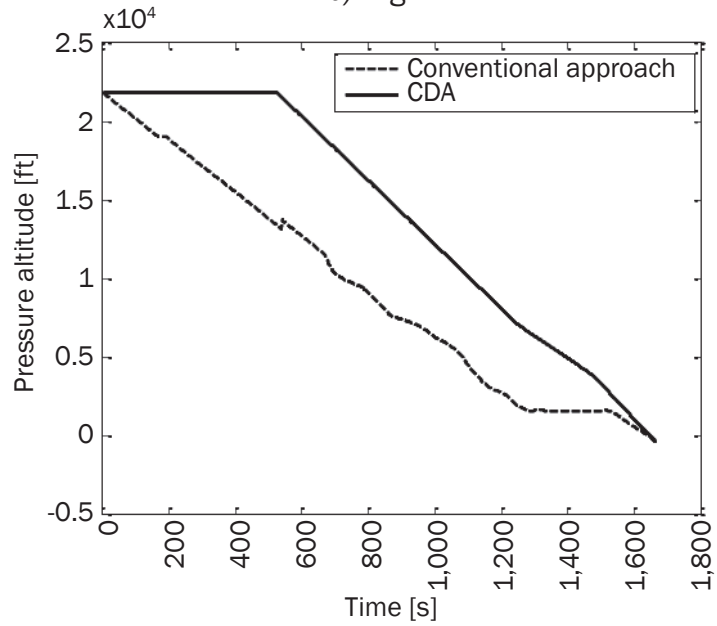

d) Flight $D$

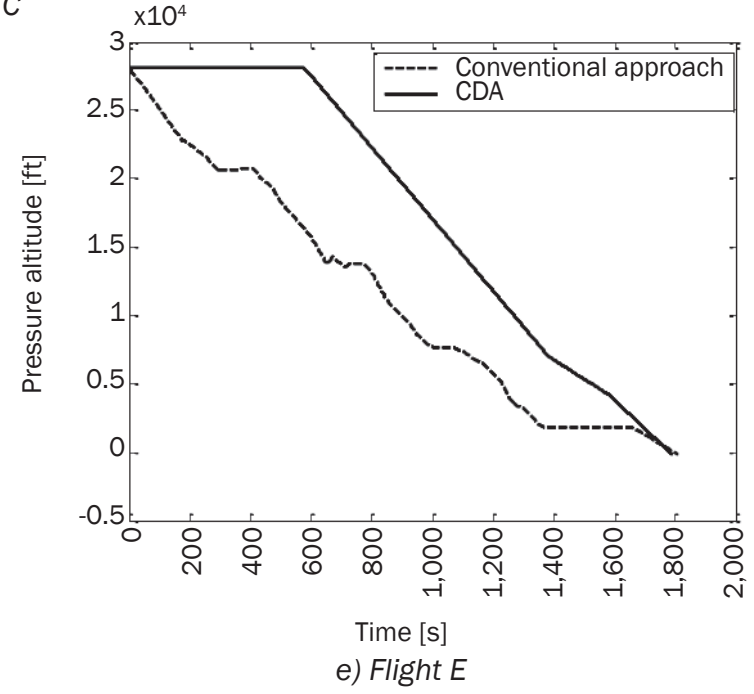

Figure 10 - Vertical trajectory profiles for A E flights 
trajectory of five test flights. It can be seen that the CDA profiles are smoother, without level-offs at low altitude. Figure 11 represents the airspeed profiles of five test flights. Comparing to the airspeed curve of conventional approach, it is seen that the CDA increases the average speed with small fluctuation, which will also lead to lower fuel burn rates as well as a huge amount of fuel savings for the majority of flights. Meanwhile, the CDA procedure reduces the average flight time by $23.4 \mathrm{~s}$ per flight, which is another reason why a huge amount of fuel could be saved.

However, these estimations for five flights appear to be a large variation, and more specific analysis for each flight should be conducted:

a) It is noted that the CDA procedure of flight $C$ exhibits negative fuel savings, as listed in Table 8, with 71 Ib of additional fuel burn, and the possible reasons are depicted as follows.

- As can be seen from the vertical profile in Figure 10c, a short period of level flights at low altitude is the main reason of reducing fuel consumption for conventional procedure of flight $\mathrm{C}$.

- The CDA duration time of flight $\mathrm{C}$ is longer than that of the conventional approach, about 112 seconds, which consumes more fuel during this period.

- Large variation of wind speed of flight $C$ will lead to errors when estimating fuel consumption for CDA.

b) In five flights, the fuel saving ability for flight $B$ is the most remarkable one; the conclusion can be drawn that:

- The duration time of conventional approach is longer than that of CDA, about $107 \mathrm{~s}$.

- Analysing from vertical profile, the conventional procedure lasts more level or approximate level segment compared to the other flights.

- The gross weight of flight $B$ is the biggest one among five flights. Especially, compared to flight A, which has similar scenarios for other variables, the gross weight could be a variable which has an impact on fuel consumption; in other words, a speculation can be drawn that heavy aircraft benefit more on fuel savings. Such conclusion is consistent with the results from previous research [16], that wide-bodied commercial aircraft should be the target group of CDA.

c) Flight $A$ and $E$ are common approaches for two patterns.

The robustness of the procedure was evaluated by the use of values for the wind speed and the direction for the designed scenarios, aiming to simulate various wind conditions. Five scenarios include both wind environments: (1) tailwind for flight A, B, C and E; (2) headwind for flight $D$; (3) strong wind. These are shown in Table 7, and the positive results imply that CDA could reduce fuel consumption under various wind conditions.
When comparing to the result of Clark's field tests, the percentage of fuel savings in this paper are conservative. Even in some reports the reductions are more aggressive, claiming that maximum benefits reductions are compromised by over $40 \%$, which is higher than the average results given in Table 7 . Yielding these results, might be attributed to the reason that the data of reports are collected in practice, in which pilots could adjust the attitude according to the definition and requirements of the CDA, regulating the operational condition of engine, so as to reduce the fuel burn rates continuously, especially for the descent phase. Nevertheless, in this paper the fuel flow rates are estimated via sub-match method, without considering this engine transformation.

Therefore, another experiment is conducted, replacing the estimation values by minimum data records of its corresponding sub-circumstance, instead of the average values. Table 8 presents the results of minimum fuel consumption. It gives a significantly different result with substantial reduction of fuel consumption by $52.16 \%$ on average. In other words, a conclusion is inferred that more remarkable potential of fuel savings can be achieved by improving the manipulation skills and keeping the power as low as possible.

\section{CONCLUSION}

This research focused on exploring a method to evaluate the potential fuel savings for Continuous Descent Approach. In this paper, rather than mathematical modelling, a sub-match method based on historical QAR data has been proposed. A number of parameters were selected to establish the sub-conditions for flight conditions. It was demonstrated that the mean error of this method is within $3 \%$.

A case study for RNAV-CDA procedure at Shanghai Pudong Airport was presented, investigating their potential fuel savings compared to the typical "stepdown" approach. The variables of key points of CDA procedures were identified by extracting from vertical and speed profiles, and meteorological environments are also set identical to the conventional approach. In general, the result of fuel reduction estimated by the sub-match method is $217 \mathrm{lb}$ per flight for Boeing $737-800$, which is in accordance with that of the field tests in previous reports. Meanwhile, the results also further demonstrate the availability for the proposed method.

In addition, by matching with the sub-conditions from historical QAR data, five sample flights were selected to establish various scenarios, which could help to understand the benefits of different descent conditions. Different quantities of fuel savings, even negative ones, for five scenarios were estimated, and the detailed results were explained carefully by the 


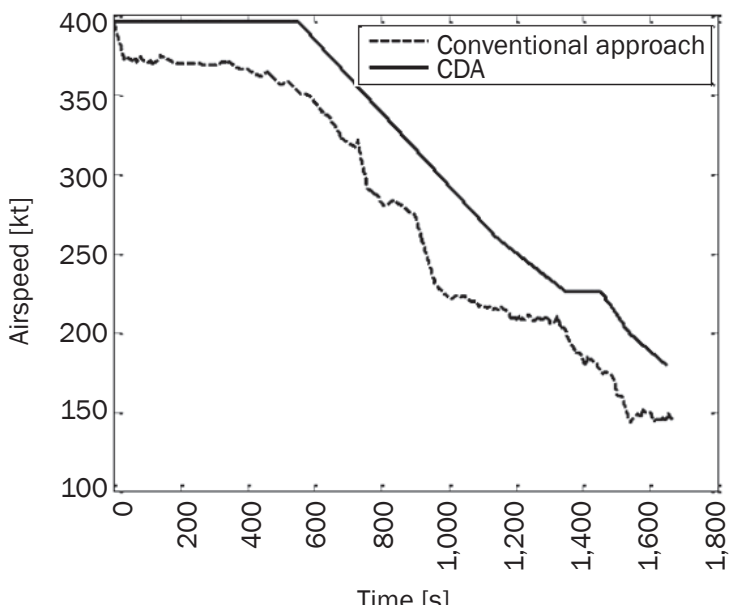

a) Flight $A$

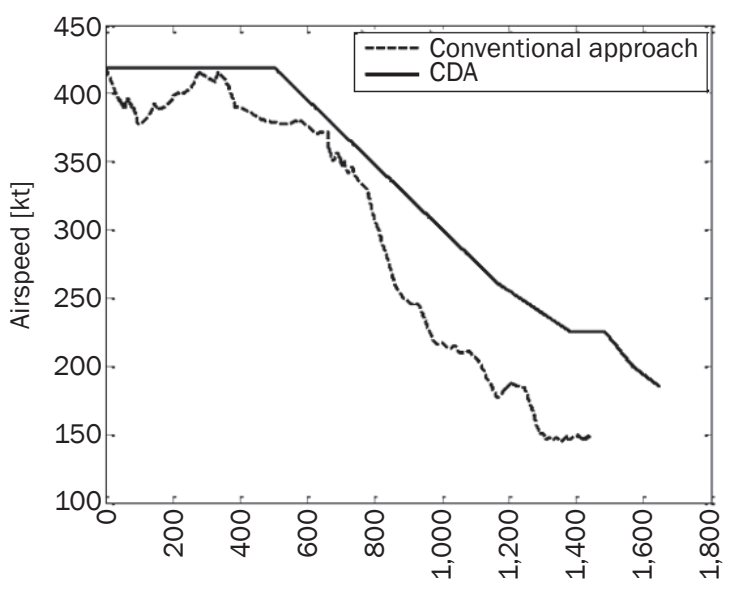

Time [s]

c) Flight $C$

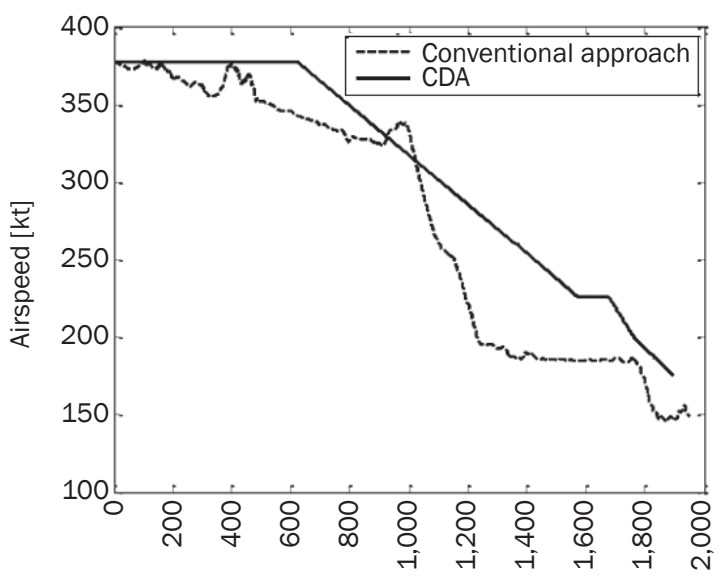

Time [s]

b) Flight $B$

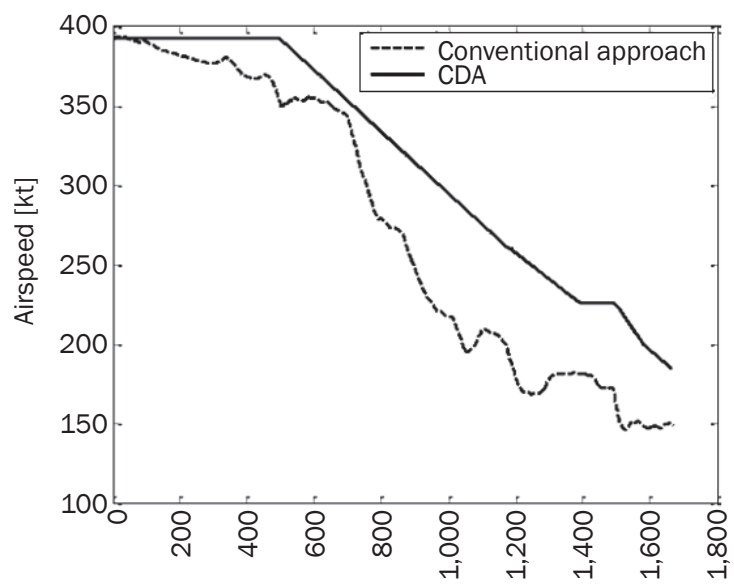

Time [s]

d) Flight $D$

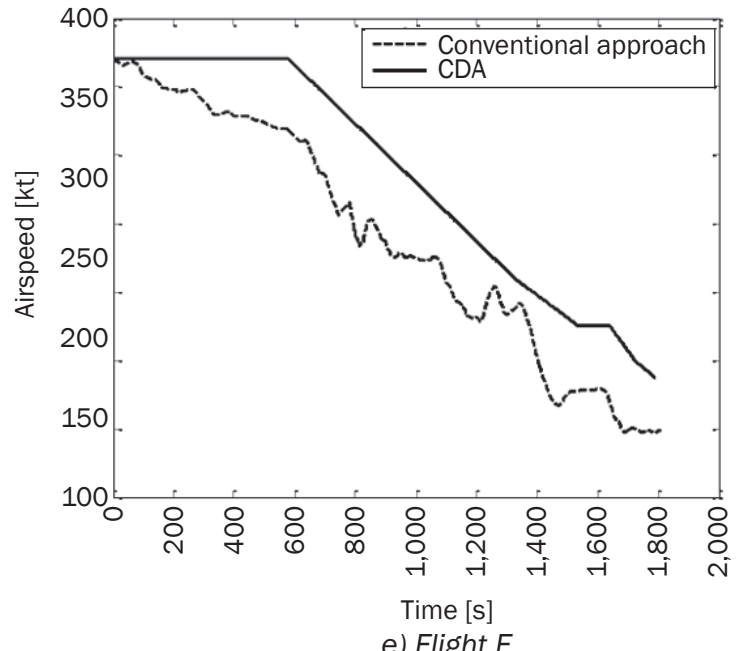

Figure 11 - Airspeed profiles for A E flights

Table 8 - Minimum fuel consumption quantities of two approach patterns

\begin{tabular}{||l|c|c|c|c|c||}
\hline & Flight A & Flight B & Flight C & Flight D & Flight E \\
\hline \hline Fuel burn of conventional approach [lb] & 1,387 & 1,806 & 1,346 & 1,665 & 1,652 \\
\hline Fuel burn of CDA [lb] & 657 & 786 & 725 & 662 & 899 \\
\hline Fuel saving quantities [lb] & 730 & 1,020 & 621 & 1,003 & 753 \\
\hline Percentage of fuel saving [\%] & 52.64 & 56.47 & 46.13 & 60.23 & 45.58 \\
\hline
\end{tabular}


relationship with the number of level-offs, descent time as well as gross weight. The impact of wind conditions on fuel consumption was examined as well. Furthermore, the fuel consumption estimated by the minimum fuel burn records exhibit $52.16 \%$ of fuel savings, which could be affected by aircraft attitude and manipulating skills. The potential application of this sub-match method helps to transfer the simulation into eventual CDA field deployment and even to extend to other new procedures or routings associated with environmental impacts.

Although this research offers a high precision method in estimating fuel consumption, and obtaining good results in simulating the CDA procedure for potential fuel savings, this work can be improved in two aspects: (1) it is difficult to analyse the fuel-optimal trajectory, which needs to be discussed further in the field test; (2) further research should be carried out considering various traffic surroundings of large sample flights with more realistic traffic mixes.

\section{ACKNOWLEDGMENTS}

This research is part of the project Abnormal Approach Formation Mechanism of Civil Aircraft Based on Flight Data (No. 61179066) supported by the Natural Science Foundation of China (NSFC), and the project of Research on Continuous Descent Approach of ATM Operational Technology supported by the technical project of ATM Bureau. Research on the key technology of tarmac target monitoring system based on infrared image in low illumination environment (No. U1633105). Research on the key technology of apron target monitoring system based on infrared image in low illumination environment (No. U1633105).

叶丽莎, 博士生, 南京航空航天大学民航学院, yelisha@ nuaa.edu.cn

曹力, 教授, 南京航空航天大学民航学院, caoli@nuaa. edu.cn

王旭辉, 工程师, 中国民航科学技术研究院, wangxh@ mail.castc.org.cn

\section{基于 $Q A R$ 数据的持续下降进近的油耗评估}

燃油消耗是评价民用航空目前和未来技术的一个重要 方面。连续下降法 $(C D A)$ 作为一种新概念的代表, 其燃油 经济性的评估方法是十分必要的。但是由于没有实际运行 数据, 很难证实传统的燃料消耗机制是否适用。本文提出 了一种独特的量化其节油性, 并提供了在试飞前无需建模 就可以评估燃油的新方法。本文详细介绍了该方法。它从 飞机发动机固有的机械特性出发, 利用历史飞行数据而非 建模, 通过快速访问记录器( $Q A R$ )数据匹配飞行条件来预 测燃油流量。仿真结果得出对传统进近预测燃料消耗的误 差仅为 $\pm 0.73 \%$ 。为了验证该方法的有效性, 本文以设计 的 $C D A$ 程序为例进行了实例分析。对基准场景下的燃料消 耗量进行估计, 分析变量对燃料消耗量的影响。预测节约 的燃油与实飞的结论一致。该分析缩短了新技术的验证周 期与成本，有助于支持航空交通管理部门对现场实飞的决 策。
关键词: 燃油消耗, 持续下降进近, 飞行数据

\section{REFERENCES}

[1] ICAO Secretariat. Aviation's Contribution to Climate Change. Montreal: International Civil Aviation Organization; 2010. p. 37-65.

[2] FAA. NextGen Implementation Plan. Air Transportation Facilities; 2013. Available from: http://medcontent. metapress.com/index/A65RM03P4874243N.pdf

[3] Joint Planning and Development Office. Next Generation Air Transportation System Integrated Plan. Joint Planning and Development Office; 2004. Available from: http://www.jpdo.aero

[4] Brooker P. SESAR and NextGen: Investing In New Paradigms. Journal of Navigation. 2008;61(2): 195-208.

[5] Yoder T. Development of aircraft fuel burn modeling techniques with applications to global emissions modeling and assessment of the benefits of reduced vertical separation minimums. MS Thesis. Dept. of Aeronautics and Astronautics, MIT, Cambridge, MA; 2007.

[6] Ramasamy S, Sabatini R, Gardi A, Kistan T. Next Generation Flight Management System for Real-Time Trajectory Based Operations. Applied Mechanics \& Materials. 2014;629(629): 344-349.

[7] Oaks R, Ryan H, Paglione M. Prototype Implementation and Concept Validation of a 4-D Trajectory Fuel Burn Model Application. AIAA Guidance, Navigation, and Control Conference, Toronto, Ontario Canada; 2010. p. 1-17.

[8] Coppenbarger RA, Mead RW, Sweet DN. Field Evaluation of the Tailored Arrivals Concept for Datalink-Enabled Continuous Descent Approach. Journal of Aircraft. 2015;46(4): 18-20.

[9] Novak D, Bucak T, Radišić T. Development, Design and Flight Test Evaluation of Continuous Descent Approach Procedure in FIR Zagreb. Promet - Traffic \& Transportation. 2009;21(5): 319-329.

[10] Errico A, Vito VD, Federico L. Study on continuous descent operation for efficient air transport system. $16^{\text {th }}$ AIAA Aviation Technology, Integration, and Operations Conference; 2016.

[11] Clarke JP, Bennett D, Elmer K, et al. Development, Design, and Flight Test Evaluation of a Continuous Descent Approach Procedure for Nighttime Operation at Louisville International Airport. Report number: PARTNER-COE-2005-002, 2006.

[12] EUROCONTROL. User Manual for the Base of Aircraft Data (BADA), Revision 3.11. EEC Technical/Scientific, Brétigny-sur-Orge, France. Report number: 13/04/1601, 2013.

[13] Chatterji GB. Fuel Burn Estimation Using Real Track Data. $11^{\text {th }}$ AIAA Aviation Technology, Integration, and Operations (ATIO) Conference, VA, 20-22 Sep. 2011, Virginia Beach, VA.

[14] Nikoleris T, Chatterji GB, Coppenbarger R. Comparison of Fuel Consumption of Descent Trajectories under Arrival Metering. Journal of Aircraft. 2013;53(6): 18531864.

[15] Patterson J, Noel G, Senzig D, et al. Analysis of ICAO Departure Profile Using Real-Time Cockpit Flight Data Recorder Information. Transportation Research Board 
$87^{\text {th }}$ Annual Meeting. Transportation Research Board Paper; 2008.

[16] Clarke JPB, et al. Continuous Descent Approach: Design and Flight Test for Louisville International Airport. Journal of Aircraft. 2004;41(5): 1054-1066.

[17] Mazin I. Fuel and Emission Benefits for Continuous Descent Approaches at Schiphol. Master thesis. University of Delft; 2016.
[18] Shresta S, Neskovic D, Williams SS. Analysis of Continuous Descent Benefits and Impacts During Daytime Operations. $8^{\text {th }}$ USA/Europe Seminar on Air Traffic Management Research and Development (ATM2009), June 29-July 2, 2009, Napa, CA.

[19] Clarke JPB, Brooks J, Nagle G, et al. Optimized Profile Descent Arrivals at Los Angeles International Airport. Journal of Aircraft. 2013;50(2): 360-369. 